\title{
Solitary gastric hamartomatous polyp and upper gastrointestinal haemorrhage: an exceptional presentation of an unusual diagnosis
}

\author{
J.C. Erdozain, J.J. Sánchez-Ruano, A.L. San Román, D. Boixeda, \\ V.F. Moreira and A.G. Plaza
}

Servicio de Gastroenterología, Hospital Ramón y Cajal, 28034 Madrid, Spain

\begin{abstract}
Summary: A case of solitary gastric hamartomatous polyp, presenting as upper gastrointestinal haemorrhage, is reported. Both the entity itself, and the clinical presentation, are exceptional. The significance of the solitary gastric hamartomatous polyp and implications of its diagnosis are discussed.
\end{abstract}

\section{Introduction}

Juvenile polyps are hamartomatous lesions, characterized by an excessive growth of connective tissue stroma of the lamina propria. ${ }^{1,2}$ They may present as an isolated entity, or as part of juvenile polyposis, hereditary or otherwise. ${ }^{3}$

The solitary gastrointestinal polyp usually affects the rectum. It is rarely described in other areas. Its presence in the stomach may be considered exceptional. ${ }^{4-6}$

Clinical presentation varies widely, from an incidental diagnosis to intestinal obstruction or chronic gastrointestinal bleeding with iron deficiency anaemia. ${ }^{4}$

Our patient presented with brisk, massive and exsanguinating upper gastrointestinal haemorrhage, which required surgical intervention. To our knowledge, this is the first report of such a presentation of this rare condition.

\section{Case report}

A 15 year old white male presented with haematemesis. His previous medical history was uneventful. After the ingestion of $500 \mathrm{mg}$ of acetylsalicylic acid, he felt a sudden epigastric pain, followed by the vomiting of bright red material in large quantities.

Physical examination showed an alert, pale, intellectually healthy young male. No mucocutaneous lesions were present. His blood pressure was $100 / 60 \mathrm{mmHg}$, and his heart frequency 110 beats per minute. A nasogastric tube was inserted,

Correspondence: J.J. Sánchez Ruano, M.D., San Modesto 46 6-B, Madrid 28034, Spain.

Accepted: 22 May 1990 evacuating about $250 \mathrm{cc}$ of bright red blood. Rectal examination was positive for melaena.

Initial routine laboratory values were normal, except for a haemoglobin level of $10.8 \mathrm{~g} / \mathrm{dl}$. An upper gastrointestinal fibroscopy showed a $2 \mathrm{~cm}$ fundic polyp, which sometimes prolapsed into the oesophagus, with a fresh clot on its surfaces Polypectomy was not performed due to technica problems.

Twenty four hours later, gastric aspirate was still bloody, and the haemoglobin was $6.7 \mathrm{~g} / \mathrm{dl}$. Two units of packed red blood cells were tranfused. Shortly afterwards, the patient experienced a further episode of haematemesis. He appeared pale and sweaty. His blood pressure was $80 / 50 \mathrm{mmHg}$, and his haemoglobin was $6.1 \mathrm{~g} / \mathrm{dl}$.

Surgical intervention was considered necessary, and an upper polar gastrectomy was performed, excising a polyp which measured $2.3 \mathrm{~cm}$, and continuously oozed fresh blood.

This structure corresponded histologically to a hamartomatous polyp, with proliferating and dilated cystic glands, separated by abundant and congested stroma, infiltrated by plasma cells and lymphocytes. A subsequent small bowel contrast $\mathrm{X}$-ray examination and a colonoscopy failed to show any polypoid structures.

\section{Discussion}

The so-called juvenile polyps are hamartomatous lesions, characterized by a uniform non-lobulated surface, and, histologically, a rich stroma surrounding multiple mucous glands, and infiltrated by a variable number of lymphocytes, plasma cells, neutrophils and eosinophils.,

Although they may be found at any age, juvenile 
polyps are typically found in children and constitute the majority of polyps in this age group.

Juvenile polyps may present as solitary polyps or, much more usually, in the context of a juvenile polyposis syndrome. If the polyp is isolated, the rectum is the common site. Its presence in the stomach is considered exceptional. ${ }^{4-6,8}$

Gastric polyps of any kind are not a frequent finding ( $2 \%$ of upper gastrointestinal endoscopies, and $0.4 \%$ of necropsies). ${ }^{9}{ }^{910}$ The majority of them are hyperplastic $(75-90 \%)$, followed by adenomas. Gastric hamartomatous polyps are usually diagnosed in juvenile polyposis syndromes. Up to $25 \%$ of Peutz-Jeghers syndrome patients show gastric polyps." The finding of tiny fundic polyps in tuberous sclerosis has also been noted. ${ }^{12}$

In our patient, the presence of other gastrointestinal polyps was excluded. He did not show cutaneous lesions suggestive of Peutz-Jeghers syndrome or Pringle's adenoma. There was also no history of seizures and his intellectual function was normal. These last three facts, exclude the diagnosis of tuberous sclerosis. His siblings were radiologically examined, and no gastrointestinal polyps could be demonstrated. Cutaneous lesions were also absent. In our opinion, our patient does not have a juvenile polyposis syndrome.

Hamartomatous polyps usually are asymptomatic, and are diagnosed as an incidental finding. However, they may occasionally present as an intestinal obstruction or as anaemia secondary to chronic blood loss. Their stroma is richly vascular, explaining their bleeding tendency. ${ }^{13,14}$ We have not been able to find any report of hamartomatous polyp presenting as massive upper gastrointestinal bleeding.

Given that juvenile polyps are benign lesions, these structures may reach a considerable size $(>5 \mathrm{~cm})$ when first detected. Their non-specific endoscopic appearance means diagnosis has to be by histological examination. ${ }^{7} \mathrm{~A}$ tendency towards malignant change has been reported in juvenile polyposis cases, especially in gastric and periampullary polyps. ${ }^{7,14}$ Whenever possible, these juvenile polyps should be endoscopically excised. If this is considered unfeasible, only the need for histological confirmation of its nature and the presence of symptoms make a laparotomy necessary.

\section{References}

1. Morson, B.C. \& Dawson, I.M.P. In: Gastrointestinal Pathology. Blackwell Scientific Publications, London, 1972.

2. Rotterdam, H. \& Sommers, S.C. In: Biopsy Diagnosis of the Digestive Tract. Raven Press, New York, 1981, p. 101.

3. Watanabe, A., Nagashima, H., Motoi, M. \& Ogawa, K. Familial juvenile polyposis of the stomach. Gastroenterology 1979, 77: $148-151$.

4. Boland, C.R., Itzkowitz, S.H. \& Kim, Y.S. Colonic polyps and the gastrointestinal polyposis syndromes. In: Sleisenger, M.H. \& Fordtram, J.S. (eds) Gastrointestinal Disease. 4th Ed. W.B. Saunders Co., Philadelphia, 1989, pp. 1483-1518.

5. Kuwano, H., Takano, H. \& Sugimachi, K. Solitary PeutzJeghers type polyp of the stomach in the absence of familial polyposis coli in a teenage boy. Endoscopy 1989, 21: 188-190.

6. Marcheggiano, A., Iannoni, C., Agnello, M., Paoluzi, P. \& Pallone, F. Solitary juvenile polyp of the stomach. Hum Pathol 1986, 17: 1077-1078.

7. Beacham, Ch.H., Shields, H.M., Raffensperger, E.C. \& Enterline, H.T. Juvenile and adenomatous gastrointestinal polyposis. Dig Dis Sci 1978, 23: 1137-1143.

8. Carfagno, G. Solitary polypoid hamartoma of the oxyntic mucosa of the stomach. Pathol Res Pract 1987, 182: 326-330.

9. Marshak, R.H. \& Feldman, F. Gastric polyps. Am J Dig Dis 1965, 10: 909.

10. Blackstone, M.O. Gastric polyps. In: Blackstone, M.O. Endoscopic Interpretation. Normal and Pathologic Appearances of the Gastrointestinal Tract. Raven Press, New York, 1984, pp. $158-169$.

11. Bartholomew, L.G., Moore, C.E., Dahlin, D.C. \& Waugh, J.M. Intestinal polyposis associated with mucocutaneous pigmentation. Surg Gynecol Obstet 1962, 115: 1.

12. Kizibuchi, $K$. High incidence of fundus hamartoma and clinical significance score in tuberous sclerosis. Brain Dev 1986, 8: 509-517.

13. Davis, G.R. Neoplasms of the stomach. In: Sleisenger, M.H. \& Fordtram, J.S. (eds) Gastrointestinal Disease, 4th Ed. W.B. Saunders, Philadelphia, 1989, pp. 745-772.

14. Stemper, T.J., Kent, T.H. \& Summers, R.W. Juvenile polyposis and gastrointestinal carcinoma. A study of a kindred. Ann Intern Med 1975, 83: 639-646. 